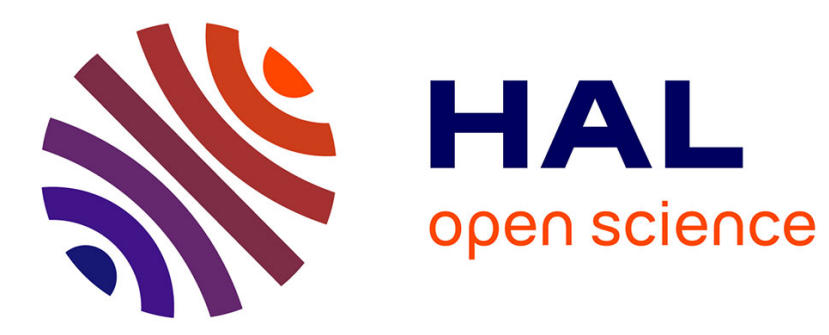

\title{
Modeling tsunami propagation and the emplacement of thumbprint in an early Mars ocean
}

F. Costard, A. Séjourné, Karim Kelfoun, Stephen M. Clifford, F. Lavigne, Ilaria Di Pietro, S. Bouley

\section{- To cite this version:}

F. Costard, A. Séjourné, Karim Kelfoun, Stephen M. Clifford, F. Lavigne, et al.. Modeling tsunami propagation and the emplacement of thumbprint in an early Mars ocean. Journal of Geophysical Research. Planets, 2017, 122 (3), pp.122(3):633-649 (IF 3,11). 10.1002/2016JE005230 . hal-01520508

\section{HAL Id: hal-01520508 \\ https://hal.science/hal-01520508}

Submitted on 3 Jan 2022

HAL is a multi-disciplinary open access archive for the deposit and dissemination of scientific research documents, whether they are published or not. The documents may come from teaching and research institutions in France or abroad, or from public or private research centers.
L'archive ouverte pluridisciplinaire HAL, est destinée au dépôt et à la diffusion de documents scientifiques de niveau recherche, publiés ou non, émanant des établissements d'enseignement et de recherche français ou étrangers, des laboratoires publics ou privés. 


\section{Journal of Geophysical Research: Planets}

\section{RESEARCH ARTICLE \\ 10.1002/2016JE005230 \\ Modeling tsunami propagation and the emplacement of thumbprint terrain in an early Mars ocean}

Key Points:

- Geomorphological characteristics of thumbprint terrains are similar to terrestrial lobate tsunami deposits

- Numerical modeling of impact-generated tsunamis demonstrates agreement between the predicted and observed distribution of lobate deposits - Arcuate pattern of thumbprint terrains can be explained by multiple reflected and refracted waves from several identified impact craters

Supporting Information:

- Supporting Information S1

- Movie S1

- Data Set S1

- Data Set S2

- Data Set S3

Correspondence to:

F. Costard,

francois.costard@u-psud.fr

\section{Citation:}

Costard, F., A. Séjourné, K. Kelfoun, S. Clifford, F. Lavigne, I. Di Pietro, and S. Bouley (2017), Modeling tsunami propagation and the emplacement of thumbprint terrain in an early Mars ocean, J. Geophys. Res. Planets, 122, 633-649, doi:10.1002/2016JE005230.

Received 8 JUL 2016 Accepted 25 FEB 2017 Accepted article online 7 MAR 2017 Published online 25 MAR 2017

\author{
Francois Costard ${ }^{1}$ (D) Antoine Séjourné ${ }^{1}$, Karim Kelfoun ${ }^{2}$ (D) Stephen Clifford ${ }^{3}$ (D) Franck Lavigne ${ }^{4}$, \\ llaria Di Pietro ${ }^{5}$, and Sylvain Bouley ${ }^{1}$ \\ ${ }^{1}$ GEOPS, Université Paris-Sud, CNRS, Orsay, France, ${ }^{2}$ Laboratoire Magmas et Volcans, OPGC, UBP-IRD-CNRS, Aubière, France, \\ ${ }^{3}$ Lunar and Planetary Institute, Houston, Texas, USA, ${ }^{4}$ Université Paris 1 Panthéon-Sorbonne Laboratoire de Géographie \\ Physique, Meudon, France, ${ }^{5}$ Università degli Studi “G. D'Annunzio" di Chieti-Pescara IRSPS, Pescara, Italy
}

Abstract The identification of lobate debris deposits in Arabia Terra, along the proposed paleoshoreline of a former northern ocean, has renewed questions about the existence and stability of ocean-sized body of water in the early geologic history of Mars. The potential occurrence of impact-generated tsunamis in a northern ocean was investigated by comparing the geomorphologic characteristics of the Martian deposits with the predictions of well-validated terrestrial models (scaled to Mars) of tsunami wave height, propagation direction, runup elevation, and distance for three potential sea levels. Our modeling suggests several potential impact craters $\sim 30-50 \mathrm{~km}$ in diameter as the source of the tsunami events. Within the complex topography of flat-floored valleys and plateaus along the dichotomy boundary, the interference of the multiple reflected and refracted waves that are observed in the simulation may explain the origin of the arcuate pattern that characterizes the thumbprint terrain.

Plain Language Summary The possibility that a large ocean once occupied the Martian northern plains is one of the most important and controversial hypotheses to have originated from the exploration of Mars. We mapped lobate deposits, which appear and are potential tsunami deposits associated with the existence of a former ocean. We identified the most probable crater sources of the proposed tsunami deposits from a numerical modeling. We tested the ability of the tsunami hypothesis to explain the origin and location of the previously enigmatic "thumbprint terrain" of northern Arabia Terra which our models suggest were formed by the interaction of the refracted tsunami waves with those reflected by the shore and offshore islands/obstacles. The age of the deposits is determined by the latest crater dating techniques. It provides evidence of the existence of Martian ocean as recently as Early Amazonian ( 3 Ga), which has implications for understanding the volatile inventory Mars, its hydrologic and climatic evolution, and the potential for the origin of survival of life.

\section{Introduction}

The possibility that a large ocean once occupied the northern plains of Mars has been proposed [Parker et al., 1993; Baker et al., 1991; Clifford and Parker, 2001] based on geomorphological evidence from Viking Orbiter images and topographic data from the Mars Orbiter Laser Altimeter [Head et al., 1999]. The geomorphic evidence consists of sedimentary plains [Lucchitta et al., 1986] and a nested set of plains margins interpreted as paleoshorelines [Parker et al., 1993]. The two most prominent examples of these margins, which are located along the highland/lowland boundary, are Contact 1 (at $-1680 \mathrm{~m}$ elevation $\pm 1700 \mathrm{~m}$ ) and Contact 2 (at $-3760 \mathrm{~m}$ elevation $\pm 560 \mathrm{~m}$ ) [Parker et al., 1993; Clifford and Parker, 2001; Head et al., 1999]. The possibility that the northern plains may have hosted a recurrent former ocean is one of the most interesting and controversial hypotheses to have originated from the exploration of Mars.

The Vastitas Borealis formation (VBF) (Figures $1 \mathrm{~b}$ and 2) is a $\sim 100 \mathrm{~m}$ thick sedimentary deposit that covers much of the northern plains. It is believed to be the depositional remnant of multiple episodes of outflow channel flooding [Carr and Head, 2003], which peaked during the transition between the Late Hesperian and Early Amazonian ( 3 Gyr) but persisted well into the Late Amazonian (as recently as the last $\sim 100 \mathrm{Myr}$ [Warner et al., 2009; Neukum et al., 2010]). Along the perimeter of the VBF is a deposit that includes sets of enigmatic parallel ridges and pitted cone chains, with individual segments up to several tens of kilometers in length, whose southernmost extent is bounded by lobate terminal deposits (Figure 1a). 


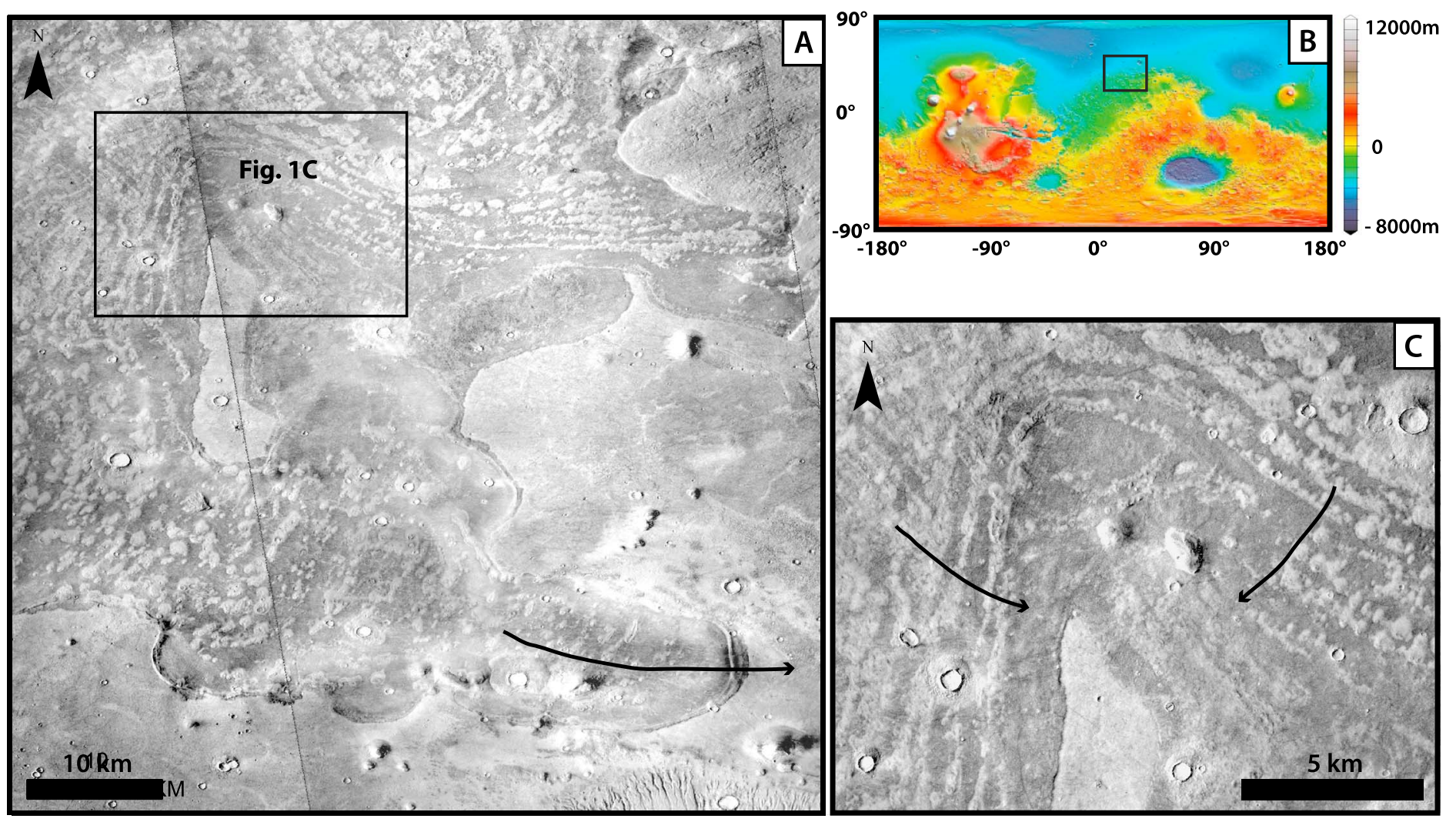

Figure 1. (a) Thumbprint terrain showing a curvilinear pattern (of high-albedo mounds; separated by low-albedo flat surfaces) and terminal lobate deposits (black arrow) in Arabia Terra. (b) Study area (black rectangle) near Arabia Terra over MOLA topographic map. CTX image P17_007835_2249. Courtesy of NASA/JPL/University of Arizona. (c) Enlargement of arcuate convex pattern of the thumbprint terrain from Figure 1a (black arrows indicating flow directions).

These morphologies are collectively described as thumbprint terrains [Lockwood et al., 1992; Kargel et al., 1995]. In this region, lobate deposits along Contact 2 in Chryse and Acidalia Planitia have been identified and named thumbprint terrains (TT) [Lockwood et al., 1992; Kargel et al., 1995]. The TT were interpreted as mudflows [Jöns, 1986], mud volcanoes [Tanaka et al., 2014; Salvatore and Christensen, 2014], moraines, or ice-cored ridges associated with a former glacial environment [Lucchitta, 1981; Rossbacher and Judson, 1981], but their exact origin is still under debate.

More recently, the $\Pi$ were interpreted as impact-generated tsunami deposits associated with a Hesperianage ocean [Rodríguez et al., 2016]. In an independent and concurrent effort, we first have mapped at highresolution northern Arabia Terra [Costard et al., 2015] and, second, investigating and testing the hypothesis that these deposits originated from an impact-generated tsunami. We did this with a two-prong approach: first, by analyzing the propagation of an impact generated tsunami from several potential source craters, using numerical simulations based on well-validated terrestrial models, scaled to Mars, and, second, by comparing these predictions with the actual geographic distribution of lobate deposits and thumbprint terrain, mapped at high resolution, in northern Arabia Terra (Figure 1a).

\section{Geological Background and Tsunami Deposits on Earth}

Our study area $\left(44^{\circ}-68^{\circ} \mathrm{N} / 0^{\circ}-23^{\circ} \mathrm{E}\right)$ encompasses part of the Vastitas Borealis Formation (VBF) (Figure 2). The VBF is the most widespread formation in the northern lowlands [Tanaka et al., 2014]. Many different hypotheses have been proposed to explain its origin, although most recent studies support a sedimentary origin related to outflow channel formation and deposition [Kreslavsky and Head, 2002] or volcanic deposits [Catling et al., 2012]. Kreslavsky and Head [2002] asserted that sedimentary portion of the VBF 


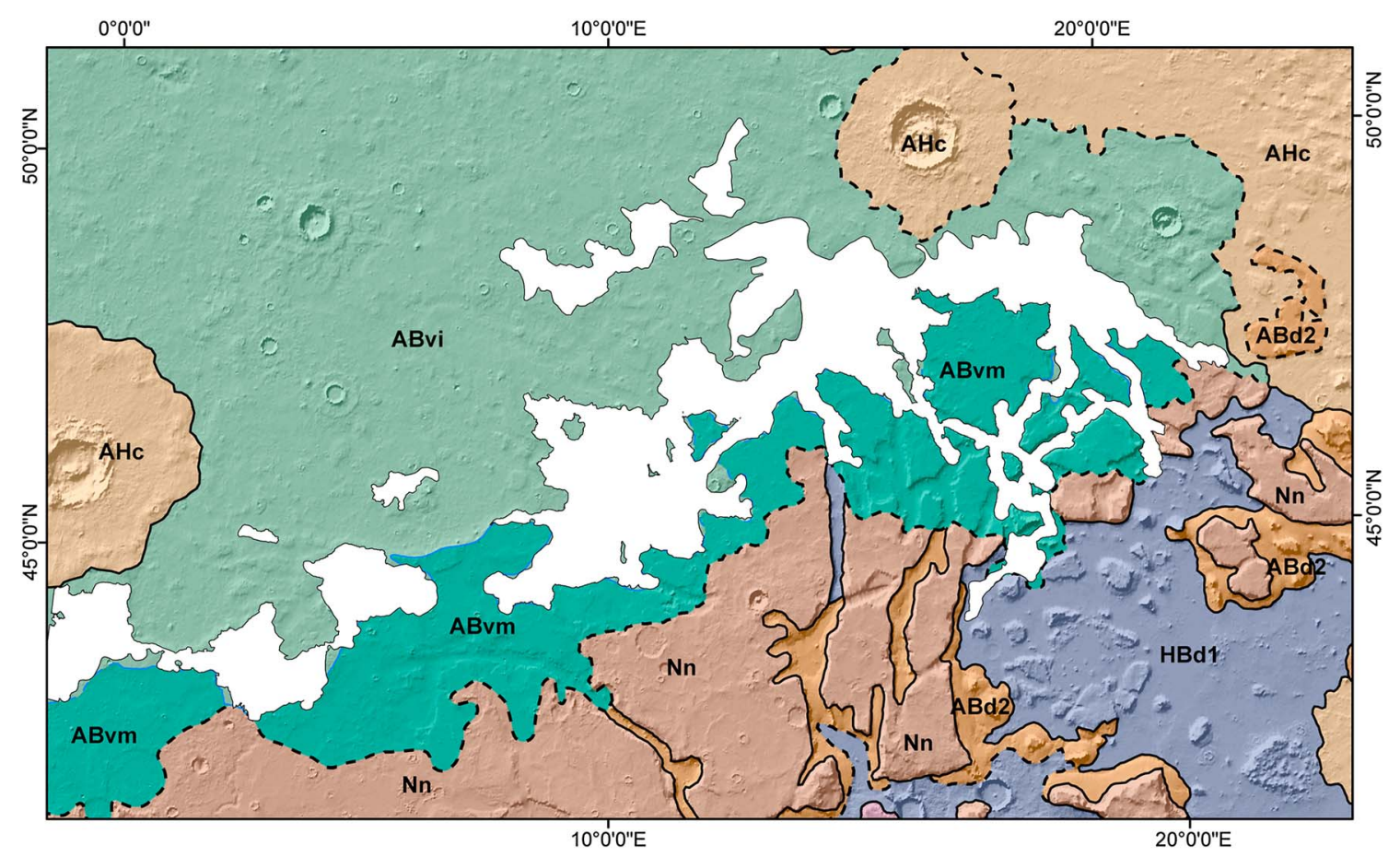

Figure 2. Geologic map of the study area in the northern plains of Mars [Tanaka et al., 2005]. The thumbprints terrains (white area) were mapped and crossed in the: Vastitas Borealis interior unit (ABvi); Vastitas Borealis marginal unit (ABvm). Geologic unit: Nn, Noachis Terra Unit; HBd1, Deuteronilus Mensae unit 1; ABd2, Deuteronilus Mensae 2 units; and HNn, Nepenthes Mensae unit. The VBF includes the Vastitas Borealis interior unit (ABvi) and the Vastitas Borealis marginal unit (ABvm). See Tanaka et al. [2005] for a more complete description. Courtesy of NASA/USGS.

(estimated to be $\sim 100 \mathrm{~m}$ thick) formed as a residue when water from the outflow channels settled, quickly froze, and then sublimated.

The VBF presents two distinct units: the VBF interior (ABvi) and the VBF marginal unit (ABvm); the former is the more extensive of the two units and hosts most of the diagnostic VBF morphological features [Salvatore and Christensen, 2014]. The ABvi unit consists of relatively bumpy, plains-forming material [Tanaka et al., 2005] that covers most of the northern plains including Vastitas Borealis and Utopia, Acidalia, and northern Arcadia Planitia. The outer parts of the interior unit include TT (Figure 2), as well as random clusters of hills mostly $<1 \mathrm{~km}$ across [Frey and Jarosewich, 1982]. Approaching the edge of the unit, the pitted cones tend to distance themselves and to occur in random and small groups until their complete disappearance.

The Vastitas Borealis marginal and interior units have a readily identifiable but poorly understood contact and postemplacement evolution. The southern limit of both VBF units collective outer margin is fairly constant in elevation $(\sim-3900 \mathrm{~m} \pm 70 \mathrm{~m}$; Figure 2$)$; hence, it may indicate the presence of an ancient standing body of water [Parker et al., 1993; Head et al., 1999; Clifford and Parker, 2001; Carr and Head, 2003]. Contact 2, mapped by Parker et al. [1993] and identified as the "Deuteronilus shoreline" by Clifford and Parker [2001], has a mean elevation of $-3760 \mathrm{~m}( \pm 236 \mathrm{~m})$, which they interpreted as the erosional remnant of a Late Hesperian/Early Amazonian ocean, formed by the discharge of the circum-Chryse outflow channels. Carr and Head [2003] argued that a potentially better indicator of the former extent of such an ocean is the Vastitas Borealis Formation, which they suggest originated from sediments that were carried by the outflow channels and deposited in the northern plains. The difference in elevation between Contact 2 and the $-3900 \mathrm{~m}( \pm 70 \mathrm{~m})$ elevation of the VBF may simply reflect the difference in the northern ocean's "sea level" and the greater depth, and further distance poleward, that the outflow channel sediments were deposited as the ocean formed. By this reasoning, the VBF is the sedimentary residue that was left after the ocean froze and sublimed away.

On Earth, tsunamis are triggered by earthquakes, volcanic eruptions, submarine landslides, or, more rarely, by meteorite impacts [Paris et al., 2009; Bryant, 2001]. The geomorphological imprints of old impact-induced 


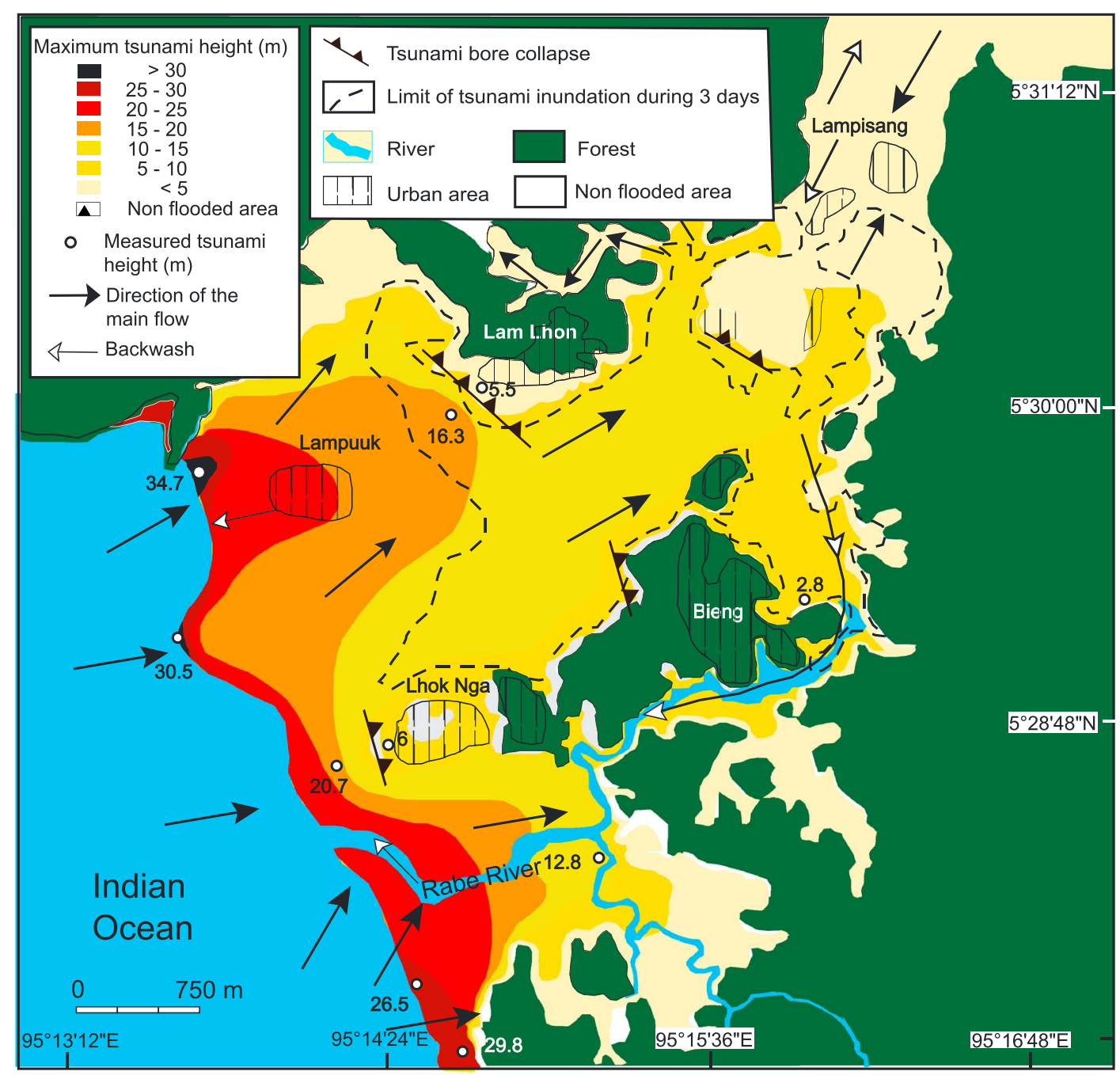

Figure 3. GIS map of lobate deposits and wave height from the tsunami in December 2004. Banda Aceh Sumatra. Modified from Lavigne et al. [2009].

tsunamis are sparse and still under debate [Hills and Goda, 1998a]. Tsunami deposits generally consist of sand and boulders, emplaced inland (inundation phase [Hills and Goda, 1998b; Bryant, 2001]) or offshore (deep-sea tsunami deposits [Cita et al., 1996]).

Tsunamis move landward in a series of wavefronts [Lavigne et al., 2009], whose energy and interaction with the shoreline topography results in different inundation distances and distributions of lobate debris (Figure 3).

The tsunami may build a lobe from scoured materials on the landward side during the uprush or a fan on the seaward side during backwash. Some of these fans are called "tsunami-scour fan" or "washover fans" when a tsunami cuts a breach, or cleans out an existing one, through a dune ridge. Backwash channels are formed just after the inundation phase when the water level is at its highest point. The backwash occurs during the recession of the water after the arrival of the first and second tsunami waves (Figure 4).

Several examples of tsunami scours have been reported from Aceh, Japan, Chile, Kamchatka, and New Zealand [Paris et al., 2009]. As shown in Figure 3, during the 2004 tsunami, multiple "tsunami-scour fan" assemblages can be formed during one inundation. If landward sand sheets infill or overlay a wetland, they can stabilize and form a low-profile hummocky topography, e.g., small sand dunes [Wassmer et al., 2006]. As exemplified in Aceh during the 2004 tsunami, the topographic extent of tsunami deposits is generally governed by the antecedent sand supply [Paris et al., 2009]. 


\section{AGU Journal of Geophysical Research: Planets}

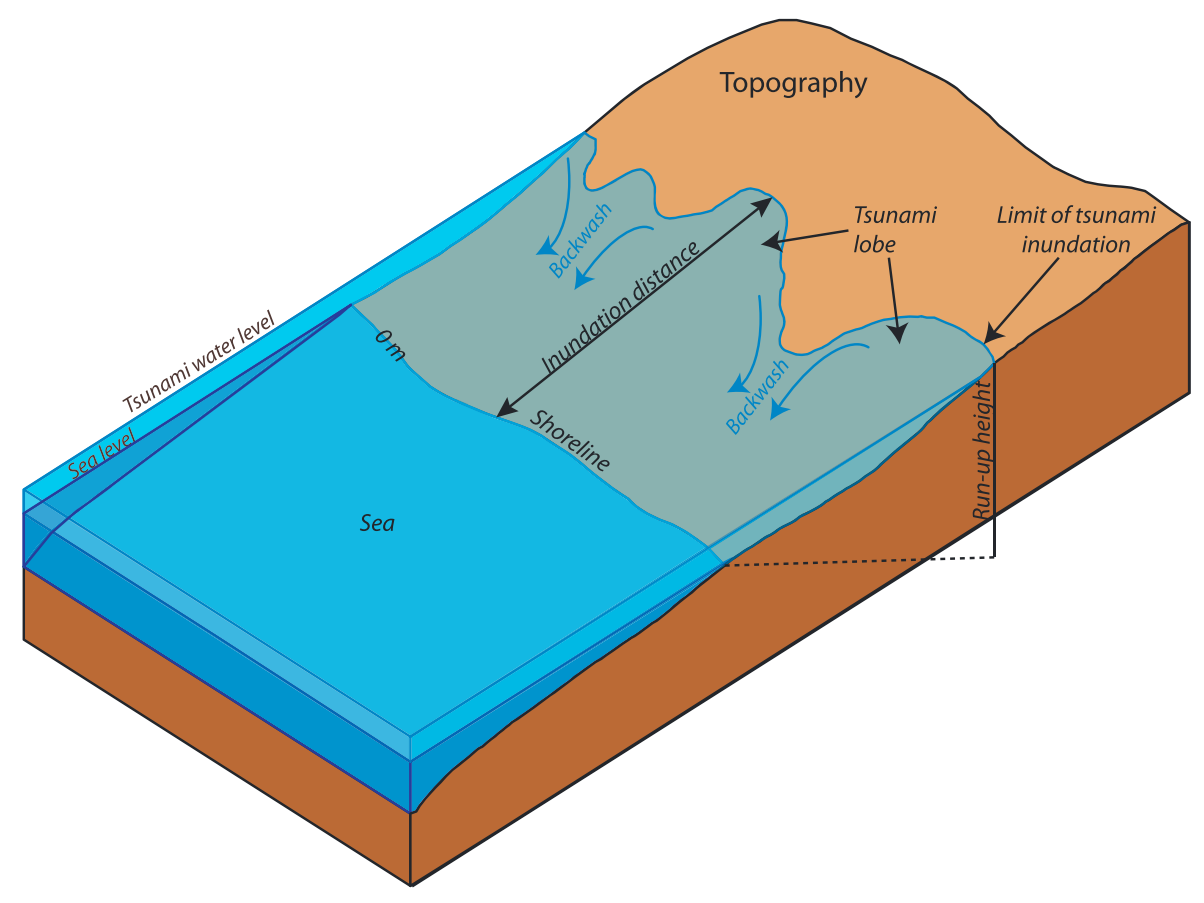

Figure 4. Schematic sketch about the different tsunami-generated landforms.

\section{Data and Numerical Modeling of Tsunamis}

The $\Pi$ were identified and mapped using the Context Camera (CTX) images providing a full coverage of the study area with a spatial resolution of $6 \mathrm{~m} /$ pixel [Malin et al., 2007, Figure 5]. Images from the High Resolution Stereo Camera (HRSC), 2-3 m/pixel) as well as a digital elevation model (DEM) from HRSC stereo images $(100 \mathrm{~m} /$ pixel [Neukum et al., 2004]) were used. Thermal Emission Imaging System (THEMIS) daytime and

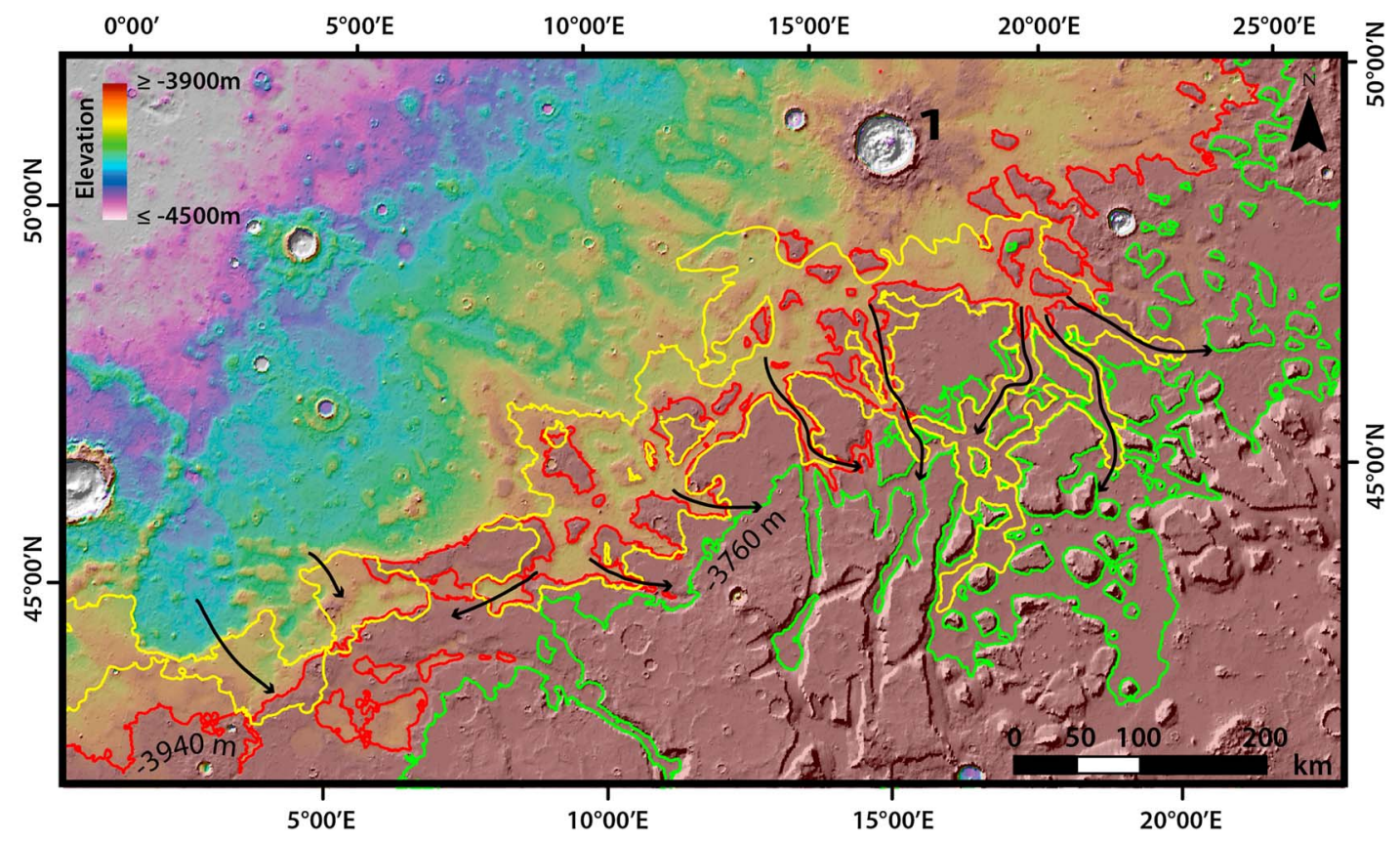

Figure 5. GIS map of thumbprint terrain, lobate deposits, and runups (yellow line) in Arabia Terra with the inferred flow directions of the tsunami waves indicated by the black arrows. The $-3940 \mathrm{~m}$ (red line) and $-3760 \mathrm{~m}$ (Contact 2; green line) topographic contour lines represent the minimum and maximum ocean shorelines assumed for our numerical simulations. The impact crater labeled "1" is one of three potential tsunami sources considered in our simulations (Figure 8). MOLA background with Cassini projection. Courtesy of NASA/JPL/USGS. 

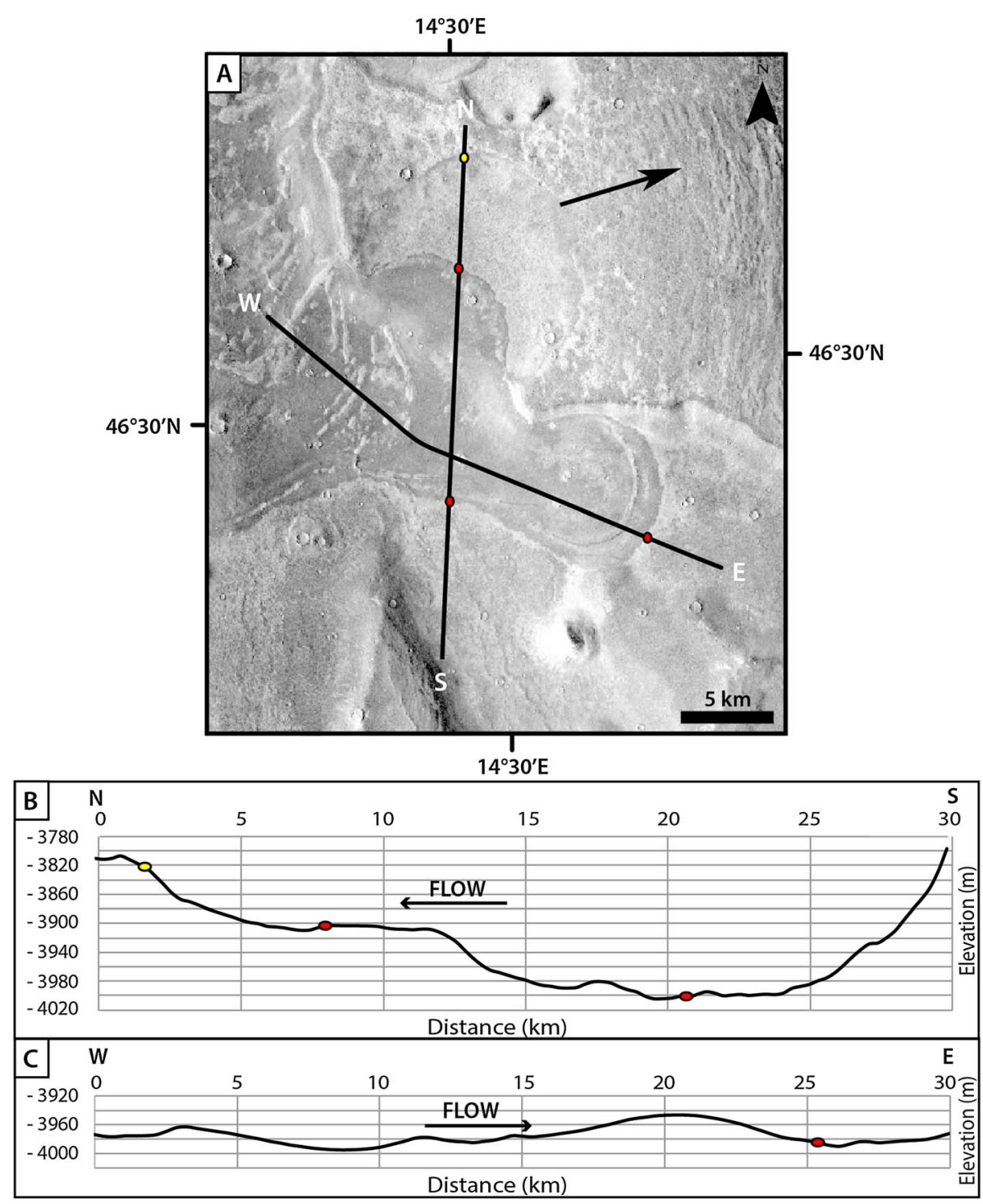

Figure 6. Close-up of overlapping lobate deposits potentially emplaced by two separate tsunami events (red and yellow dots delineate two lobes). (b) Transverse topographical profile showing a runup of $100 \mathrm{~m}$ in elevation between the valley bottom and the plateau. (c) Longitudinal topographical profile of upslope lobate deposits inside valley. CTX image B18_016788_2273. Data from MOLA laser shots. Courtesy of NASA/JPL/University of Arizona.

nighttime infrared images were also used to help to map the $\Pi(100 \mathrm{~m} /$ pixel). The Mars Orbiter Laser Altimeter (MOLA) digital elevation model was used for topographic analysis (DEM; $300 \mathrm{~m}$ of spatial resolution [Smith et al., 2001]), but further, higher-resolution topographic information was obtained through the analysis of individual MOLA laser shots (vertical resolution: $50 \mathrm{~cm}$; Figure 6a) thanks to MOLA Precision Experiment Data record (PEDR) facility developed and hosted at the Photothèque Planétaire d'Orsay (http://fototek. geol.u-psud.fr/-Mars-Orbiter-Laser-Altimeter-.html). The images and the DEM were processed, calibrated, and georeferenced (Figure 5) using the U.S. Geological Survey (USGS) Integrated Software for Imagers and Spectrometers 3 (ISIS 3) [Anderson et al., 2004].

We dated the $\pi$ unit by the application of standard crater counting techniques (Figure 7), covering an area of $\sim 44,000 \mathrm{~km}^{2}$ that included 81 craters $>1 \mathrm{~km}$ in diameter-an age that corresponds to the Early Amazonian ( $3 \mathrm{Ga})$. For the purpose of our study, we emphasize relative crater ages to determine where the $\Pi$ are in the Martian chronology. We think that the uncertainties in both the accuracy of crater age dating and the determination of absolute ages from these crater counts preclude a precise dating of a northern ocean and the timing of the tsunami events. 


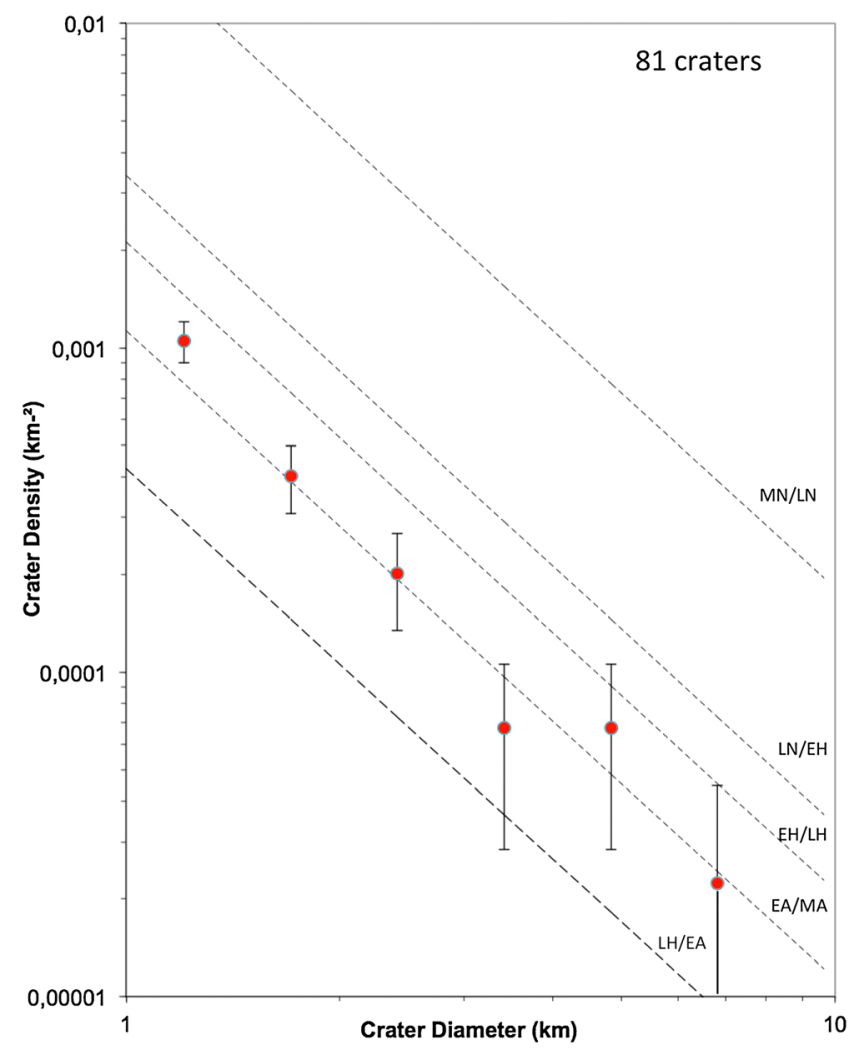

Figure 7. The incremental crater densities of the thumbprint terrain in Figure 2. The deposits are $\sim 3$ billion years old (Late Hesperian/Early Amazonian transition). The two power laws [Hartmann, 2005] given by dashed lines mark the boundaries between, from lower to upper, the Late Hesperian-Amazonian (LH-A), Early Hesperian-Late Hesperian (EH/LH), Late Noachian-Early Hesperian (LN-EH), and Middle Noachian-Late Noachian (MN/LN). Error bars represent a $1 \sigma$ interval of $(\mathrm{nj})^{2} / \mathrm{Aj}(\mathrm{nj}$ : number of crater for one interval; Aj: studied area in $\mathrm{km}^{2}$ ).
We used the numerical model VolcFlow [Kelfoun and Druitt, 2005] to compare the propagation of an ocean impactgenerated tsunami with the distribution of lobate deposits found in $\pi$ unit along the dichotomy boundary. Theoretical investigations of the potential generation and propagation of large tsunamis from meteorite impacts into a Martian northern ocean were previously conducted by Matsui et al. [2001] and lijima et al. [2014]. Later, Mahaney et al. [2010] discussed the potential occurrence of tsunami-emplaced sediments along Contacts 1 and 2, which had been identified as potential paleoocean shorelines [Parker et al., 1993; Clifford and Parker, 2001]. Although all of these studies discussed the potential for impact-generated tsunamis on Mars, no explicit geological evidence of tsunami-emplaced deposits were identified by these authors.

Given the uncertainty in the location of the impacts responsible for the generation of the tsunamis and the corresponding sea level of the paleo-ocean, we have modeled the propagation of tsunamis associated with several nearby impact craters. Three impact craters in the northern plains were considered based on their apparent age/state of degradation and locations, relative to the proposed shorelines (Figure 8 and Table 1). Geologic studies and numerical simulations of the cratering process in an ocean on Earth show that marine impact craters are wider and shallower than normal craters due to extensive infilling and show eroded rim due to the erosion by backrushing water [Gault and Sonett, 1982; Ormo et al., 2002; Shuvalov and Trubestkaya, 2002]. The selected three impact craters show a degraded rim, partially filled interiors, and lack a clear ejecta blankets (Figure 8). We do not see any scours on crater rim (which are diagnostic of marine impact crater on Earth), probably because of they are Hesperian age. The apparent lack of lobate ejecta and the presence of double or subdued rim can be either due to subsequent erosion after the withdrawal of the ocean or due to the dynamic interaction between the formation of the crater and the ocean during the impact.

These calculations were based on the present (MOLA-derived) Martian topography and ocean sea levels ranging from $-3940 \mathrm{~m}$ to $-3760 \mathrm{~m}$ in elevation, in agreement with the observed distribution of the deposits and Contact 2. We assumed that the topography was identical 3 Gyrs ago and that the effect of the erosion versus time was relatively small since the Hesperian epoch [Carr and Head, 2010]. We reconstructed the preimpact bathymetry by removing the crater and its ejecta younger than the selected impact craters from the present-day MOLA topography.

\subsection{Numerical Approach}

For our analysis, we used the numerical model VolcFlow [Kelfoun and Druitt, 2005] to compare the propagation of an ocean impact-generated tsunami with the distribution of lobate deposits found along the dichotomy boundary. The VolcFlow model was initially developed to simulate volcanic flows such as dense 


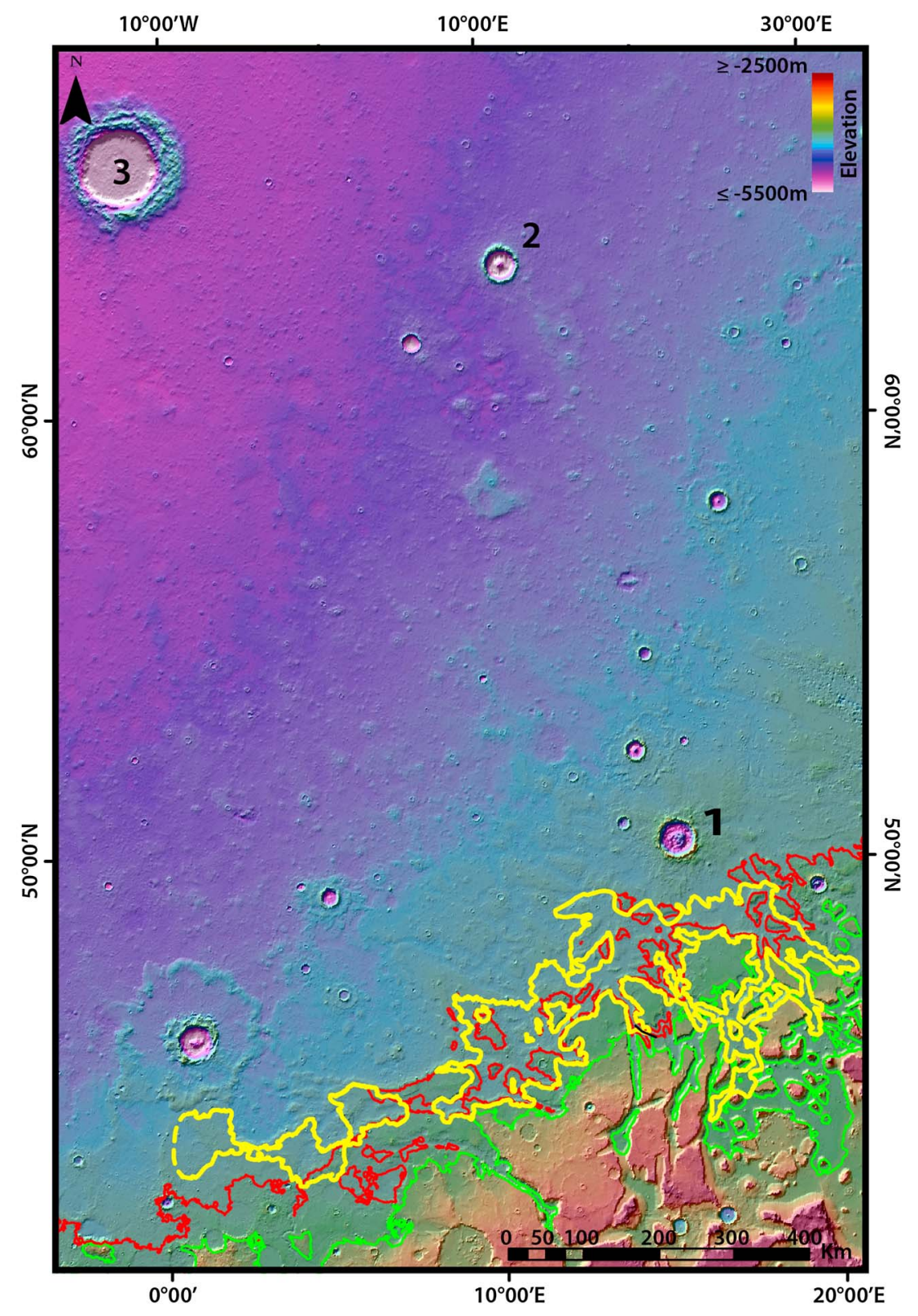

Figure 8. The locations of the three impact craters in Acidalia Planitia considered as the potential sources of the tsunamis investigated in this study. The observed distribution of $\Pi$ and terminal lobate deposits in Arabia Terra are depicted in gray. The $-3940 \mathrm{~m}$ (red line) and $-3760 \mathrm{~m}$ (Contact 2; green line) topographic contour lines represent the minimum and maximum elevations of the ocean shorelines considered in our numerical simulations. MOLA elevations are superimposed on a shaded relief map with Cassini projection. Courtesy of NASA/JPL/USGS.

Table 1. Properties of Three Impact Craters in Acidalia Planitia That May Have Triggered a Tsunami in Arabia Terra

\begin{tabular}{lccc} 
Impact Crater Location & $\begin{array}{c}\text { Transient Cavity } \\
\text { Diameter/Depth }(\mathrm{km})\end{array}$ & $\begin{array}{c}\text { Depth of Ocean for } \\
\mathrm{a}-3760 \mathrm{~m} \text { Sea Level }\end{array}$ & $\begin{array}{c}\text { Depth of Ocean for } \\
\mathrm{a}-3940 \mathrm{~m} \text { Sea Level }\end{array}$ \\
\hline Crater 1: $50.52^{\circ} \mathrm{N} / 16.39^{\circ} \mathrm{E}$ & $31.25 / 9.8$ & $274 \mathrm{~m}$ & $94 \mathrm{~m}$ \\
Crater 2: $63.70^{\circ} \mathrm{N} / 10.98^{\circ} \mathrm{E}$ & $25 / 7.8$ & $822 \mathrm{~m}$ & $642 \mathrm{~m}$ \\
Crater 3: $64.88^{\circ} \mathrm{N} / 09.15^{\circ} \mathrm{W}$ & $68.7 / 21.5$ & $1198 \mathrm{~m}$ & $1018 \mathrm{~m}$ \\
\hline
\end{tabular}


pyroclastic flows and debris avalanches [Kelfoun and Druitt, 2005] and was subsequently modified for the simulation of the dynamics of tsunamis generated by volcanic destabilizations [e.g., Kelfoun et al., 2010; Giachetti et al., 2011; Nomikou et al., 2016].

The sediment load of the ocean is unknown; therefore, we have considered sediment loads ranging from an ocean of pure water to mud. The two sea levels considered in our simulations $(-3760 \mathrm{~m}$ and $-3940 \mathrm{~m})$ lie within the elevation range of Contact $2(-3760 \mathrm{~m} \pm 560 \mathrm{~m}$ in Head et al. [1999]).

The model is gravitationally scaled to Mars, which affects tsunami wave propagation (see equation (2)).

VolcFlow is based on the depth-averaged approximation of equations of mass and momentum using a topography-linked coordinate system.

$$
\begin{gathered}
\frac{\partial h_{w}}{d t}+\frac{\partial}{\partial x}\left(h_{w} u_{x}\right)+\frac{\partial}{\partial y}\left(h_{w} u_{y}\right)=0 \\
\frac{\partial}{\partial t}\left(h_{w} u_{x}\right)+\frac{\partial}{\partial x}\left(h_{w} u_{x}^{2}\right)+\frac{\partial}{\partial y}\left(h_{w} u_{x} u_{y}\right)=g h_{w} \sin \alpha_{x}-\frac{1}{2} \frac{\partial}{\partial x}\left(g h_{w}^{2} \cos \alpha_{x}\right)-\frac{T_{x}}{\rho} \\
\frac{\partial}{\partial t}\left(h_{w} u_{y}\right)+\frac{\partial}{\partial y}\left(h_{w} u_{y}^{2}\right)+\frac{\partial}{\partial x}\left(h_{w} u_{y} u_{x}\right)=g h_{w} \sin \alpha_{y}-\frac{1}{2} \frac{\partial}{\partial y}\left(g h_{w}^{2} \cos \alpha_{y}\right)-\frac{T_{y}}{\rho}
\end{gathered}
$$

where $h_{\mathrm{w}}$ is the water depth, $\mathbf{u}=\left(u_{x}, u_{y}\right)$ is the water velocity, $\alpha$ is the slope of the ocean bottom, $\rho$ the water density $\left(1000 \mathrm{~kg} \mathrm{~m}^{-3}\right)$, and $g$ is the gravity fixed at $3.71 \mathrm{~m} \mathrm{~s}^{-2}$ for Mars. The terms on the right-hand side of the equations of momentum balance indicate the effect of the weight, of the pressure gradient, and of the shear resistance, $\mathbf{T}=\left(T_{x}, T_{y}\right)$. For pure water, the effect of the viscosity is negligible, and it is not taken into account, so that $T_{x}=T_{y}=0$. In the case of an ocean of mud, $\mathbf{T}$ takes into account the mud rheology.

The scheme of VolcFlow allows an accurate resolution of these nonlinear equations as verified by the comparison of the theoretical predictions of a dambreak [Kelfoun and Druitt, 2005] and viscous flows [Cordonnier, 2015]. VolcFlow is able to simulate inland flooding. However, complex phenomena, such as wave breaking, cannot be simulated by a depth-averaged approach.

\subsection{Initial and Boundary Conditions}

The evolution of the transient cavity produced by the impact of an asteroid into an ocean is difficult to simulate.

We modeled the topography of the transient cavity (diameter and depth) based on the literature of the impact into a shallow ocean. First, the ratio of the final crater diameter to the transient cavity diameter (referred to as the collapse factor) has an average value of 1.6 in rock [Melosh, 1989]. Second, the ratio cavity diameter to cavity depth is about 3.2 as shown by laboratory experiments and modeling. The meteorite impact in unconsolidated, water-covered sedimentary targets can result in a more subdued crater morphology than inferred from statistics of known terrestrial impact craters [Gault and Sonett, 1982; Shuvalov and Trubestkaya, 2002].

The shape of the transient cavity (Figure 9a) follows a parabolic profile [Ward and Asphaug, 2000]:

$$
\begin{array}{ll}
\Delta z=\Delta z_{c}-\frac{\Delta z_{c}}{r_{\text {rim }}^{2}} \times r^{2}, & r \leq r_{\text {rim }} \\
\Delta z=0, & r>r_{\text {rim }}
\end{array}
$$

where $\Delta z_{c}$ is the maximum elevation change at the center of the impact $\left(\Delta z_{c}=\right.$ cavity depth from Table 1$)$ and $r$ is the radial distance from the crater center. The model assumes that the ejecta were emplaced after the tsunami formed.

If the water depth is large enough, the initial wave is given by Ward and Asphaug [2000]:

$$
\begin{array}{ll}
\Delta h=-r_{\text {rim }}^{2}\left(1-\frac{r^{2}}{r_{\text {rim }}^{2}}\right), & r \leq \sqrt{2} \times r_{\text {rim }} \\
\Delta h=0, & r>\sqrt{2} \times r_{\text {rim }}
\end{array}
$$

For the shallow ocean studied (Table 1), the volume of the water displaced is larger than available. The wave amplitude calculated by equation (5) is thus divided by a factor that respects mass conservation (Figure 9b). 

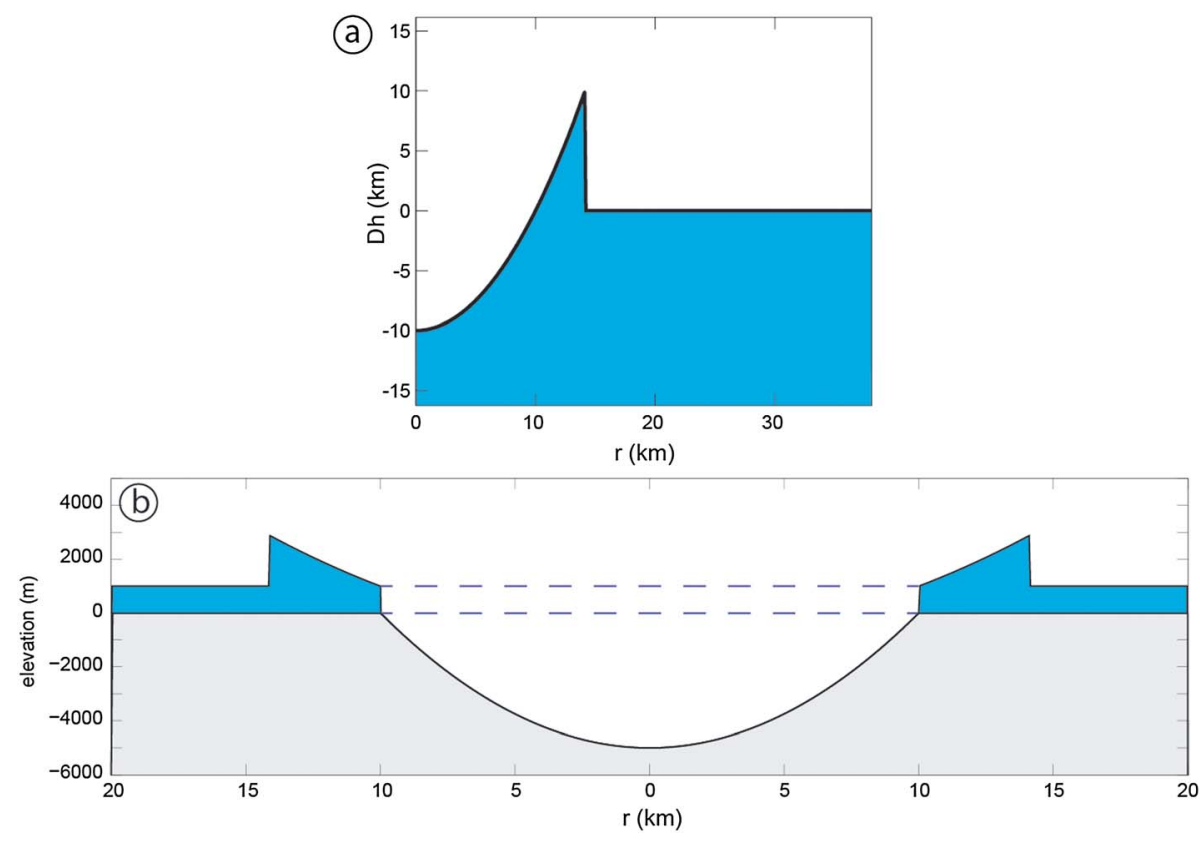

Figure 9. (a) Geometry of the initial tsunami wave in deep water. (b) Geometry of the crater and of the initial tsunami wave formed by an impact in shallow water. Water is in blue; seafloor is in gray. Dashed line represents the ocean before impact.

The wave's initial radial velocity is given by

$$
\mathbf{u}=u_{0} \frac{\Delta h}{h_{0}} \times \frac{\mathbf{r}}{r}
$$

where $u_{0}$ is the maximum velocity at the crater rim, $\mathbf{r}=\left(r_{x}, r_{y}\right)$ is the radial distance components in $x$ and $y$, and $h_{0}$ is the water depth before the impact.

To permit free propagation of waves, open boundaries are defined at the border of the domain by calculating the water velocity normal to the border, $u_{\mathrm{b}}$, from the water thickness $h_{\mathrm{w}}$ :

$$
u_{b}=2\left(c_{1}-c_{0}\right)
$$

where $c_{1}=\sqrt{g h_{w}}$ and $c_{0}$ equals the value of $c_{1}$ at $t=0$.

The initial tsunami wave propagates radially from the crater to the shore from the collapse of the ejected water from the impact (Figures 9b, 10a, and 10b). Few hours later, water fills gradually the transient cavity formed by the impact (see Movie S1 in the supporting information). As the inward propagating wave collides and rebounds at the center of the cavity, second outward tsunami wave is formed (Figure 10e and Movie S1 in the supporting information). The amplitude of the second wave may be lower or higher than that of the first wave, according to the depth of both the cavity and the ocean (Figures 10b and 10e).

The main parameter that influences the tsunami propagation is the volume displaced by the impact. It also controls the height of the tsunami when it reaches the shoreline as well as the inland inundation distance. The initial shape of the wave and the initial wave velocity play a minor role on the tsunami dynamics, except in the vicinity of the impact.

\section{Finding the Origin of the Tsunami}

\subsection{Thumbprint Terrains in Arabia Terra}

The $\pi$ unit is concentrated in the southeastern region of Acidalia Planitia and northern Arabia Terra, following Contact 2 (centered at $45^{\circ} \mathrm{N}$ and $10^{\circ} \mathrm{E}$; Figures $1 \mathrm{~b}$ and 2). The $\Pi$ form lobate deposits with runups inside valleys where they can be 10 to $20 \mathrm{~m}$ in thickness and exhibits peripheral ridges (Figure 6). Most of the time, these flows divert around preexisting topographic features [Salvatore and Christensen, 2014] and overlap mesas (Figure 1). In some cases of multiple flow activity, there is some overlapping between adjacent lobes 


\section{AGU Journal of Geophysical Research: Planets}
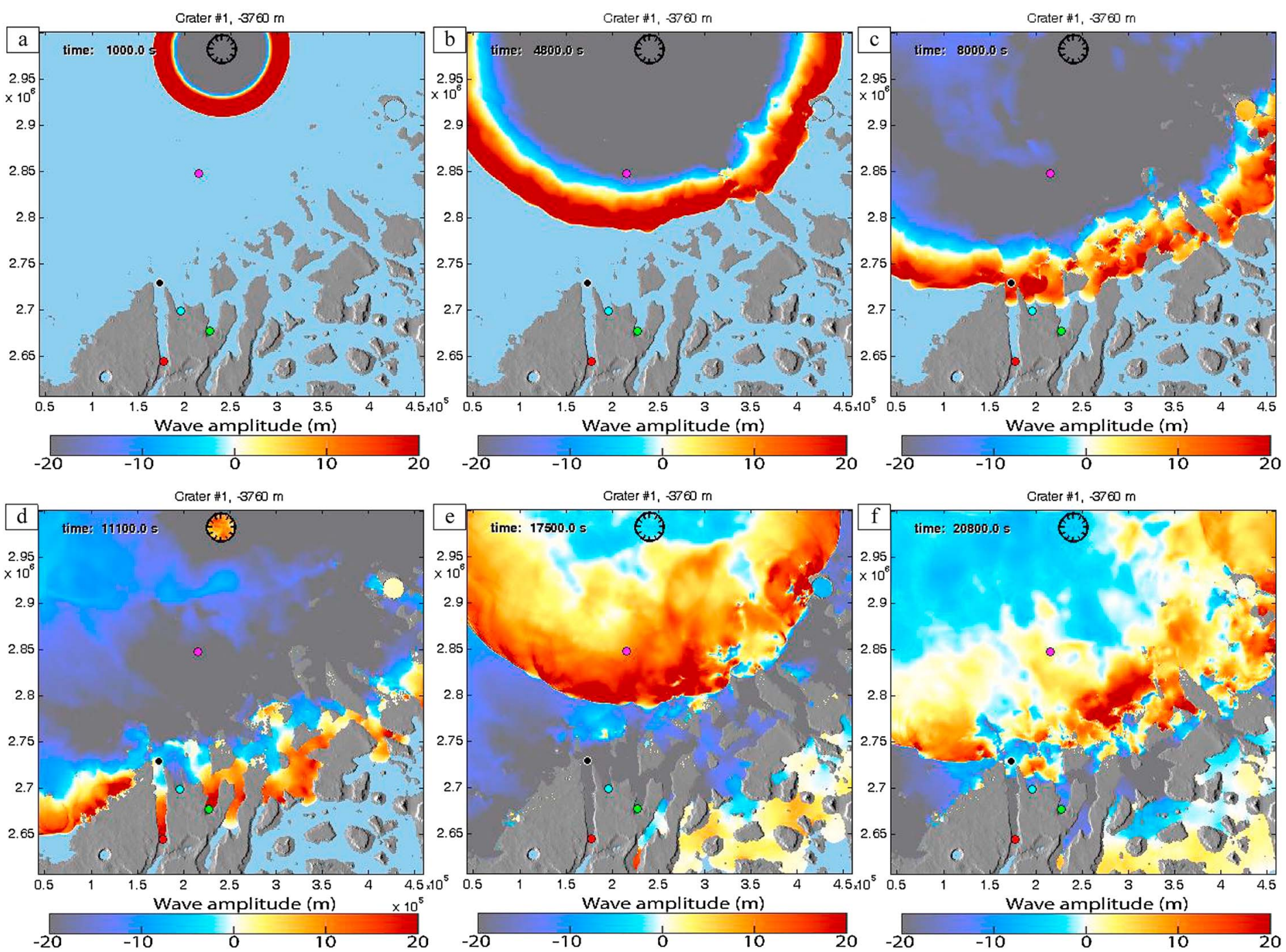

Figure 10. Propagation of the tsunami waves as a function of time. From Movie $\mathrm{S} 1 \mathrm{in}$ the supporting information. Impact \#1 ocean $-3760 \mathrm{~m}$. The second wave in Figures 10e and $10 \mathrm{f}$ corresponds to the transient cavity filled by water. Elapsed time: (a) 00:15:00 (= hour:minute:second), (b) 00:56:00, (c) 02:18:00, (d) 03:16:00, (e) 07:06:00, (f) 09:11:00. Video available in the supporting information. The light blue color is the initial water level and corresponds to the $0 \mathrm{~m}$ wave height (white) and the red color to an elevation higher than $20 \mathrm{~m}$. Colored dots correspond to the measured water thickness and wave amplitude in the supporting information.

(Figure 6a). The $\Pi$ are characterized by a curvilinear pattern of high-albedo mounds, separated by low-albedo flat surfaces (Figure 1a). In many places, the high-albedo mounds are aligned in arcuate convex patterns that terminate against the transitional hills and plateaus of the dichotomy boundary (black arrow on Figure 1c).

The $\Pi$ are brighter than the surrounding plain in daytime THEMIS (Thermal Emission Imaging System) images, and darker in THEMIS nighttime images; they are readily mapped. From the comparison of infrared night and day THEMIS images, the lobate deposits seem to have a different thermal inertia than the surrounding plains. The difference is likely due to a difference in granulometry, with the terminal lobes containing relatively finer grained sediment than the surrounding plain, The orientation of the terminal lobate deposits and the interior arcuate pattern of high-albedo mounds indicate a southward (and upslope) direction of flow (Figures $1 \mathrm{c}$ and 5).

Over the last few decades, various scenarios have been proposed to explain the origin of the mounds and alignments of the $\Pi$. They have been successively described as volcanic or glacial landforms. Suggested analogs include rootless cones, cinder cones [Frey and Jarosewich, 1982], and ice-cored moraine [Lucchitta, 1981; Scott and Underwood, 1991; Lockwood et al., 1992; Guidat et al., 2015; Souček et al., 2015]. 
However, the lack of associated glacial flow features (drumlins, kettle holes, and eskers) is inconsistent with the glacial hypothesis [Thomson and Head, 2001]. More recent studies suggest an origin with mud volcanism [Tanaka, 1997; Salvatore and Christensen, 2014]. But, the lack of volcanic sources, volcanic vents, and steep-sided cones is problematic for the volcanic hypothesis. All of these previous hypotheses provide potential explanations for the arcuate pattern geometry and the presence of individual pitted mounds in Acidalia Planitia [Salvatore and Christensen, 2014]. But Rodríguez et al. [2016] and Costard et al. [2015] have identified other characteristics that are inconsistent with these hypotheses. Based on MOLA data and high-resolution orbital images, the observation of lobate flows in the $\Pi$ that appear to originate within the northern plains and propagate around and over low-lying obstacles (runups) along the dichotomy boundary, we favor a tsunami hypothesis (Figure 6). The high elevations (runup) of these lobate flows, which have propagated down fretted valleys and overtopped low-lying mesas, indicate that the flow had both high energy and inertia (Figures 1, 6b, and $6 \mathrm{c}$ ). Based on studies of Earth analogs, neither volcanic nor glacial processes appear capable of producing such runups.

\subsection{Implications for Martian Tsunamis}

Although the propagation and depositional patterns of the tsunamis observed in Indonesia in 2004 [Lavigne et al., 2009] and Japan in 2011 [Goto et al., 2011] are smaller and more localized than those observed on Mars, the similarity of the terrestrial deposits to the Martian lobate deposits provides insights into their likely origin (Figure 3). The proposed Martian tsunami traveled as far as $150 \mathrm{~km}$ past the $-3940 \mathrm{~m}$ shoreline (see location of lobate deposits relative to potential source craters in Figure 5), flowing down valleys and over hills and plateaus with terminal lobe runup heights reaching up to $100 \mathrm{~m}$ (Figure $6 \mathrm{~b}$ ). In some valleys, the overlap of several distinct lobate deposits suggests the possibility of multiple tsunami events (Figure 6). Incised channels, $\sim 100 \mathrm{~km}$ long, are observed on some mesas and are interpreted as backwash channels (Figures 6a) that were eroded as the water receded, following the flooding event [Rodríguez et al., 2016]. The relatively thick deposits and elevated runup heights of some of the terminal lobes are expected consequences of a high-energy tsunami, which would have eroded and entrained a large volume of debris as it reached the shallower waters along the dichotomy boundary. Our detailed mapping of the distribution of lobate deposits shows that they vary in elevation from $-3940 \mathrm{~m}$ in the west to $-3760 \mathrm{~m}$ in the east (Figure 5). This suggests that the deposits were emplaced by two or more impact events, associated with different ocean sea levels in agreement with a previous study [Rodríguez et al., 2016]. Crater counts of the $\Pi$ unit indicate a crater-retention age of $\sim 3 \mathrm{Gyr}$ (see Figure 7) which corresponds to an Early Amazonian/Late Hesperian northern ocean, in agreement with the hypothesis of Parker et al. [1993].

In our model, the initial tsunami wave is formed by the water displaced by the impact, while the second wave arises from the collapse and reflooding of impact-generated transient cavity in the ocean and seafloor, similar to other models (Figure 10) [Matsui et al., 2001; lijima et al., 2014].

This behavior depends essentially on the hypothesis done for the first wave. For example, simulations with a short and high initial wave show a flow back into the crater first. At the coast, the influence of the impact first begins by a withdrawal of the sea followed by a positive wave formed by the reflowing of the crater. Other than that, the initial shape of the wave has little influence on the wave propagation, the displaced volume being the most important parameter for the wave amplitude at the shore.

The initial wave propagates radially from the crater, reaching the coast after tens of minutes up to as much as few hours depending on the location of the impact considered (Figures 10b and 10c). The velocity of the propagation of the wave was initially $60 \mathrm{~m} / \mathrm{s}$ and then decreasing to $30 \mathrm{~m} / \mathrm{s}$. Upon reaching the coast, the tsunami wave continues to propagate southward, between mesas and down narrow valleys (Figures 10c and 10d). The second tsunami waves hits the proximal coast as well (Figures 10e and 10f). Multiple reflected and refracted waves can be observed from the complex topography of the coast (Figures 10c-10f and Movie $\mathrm{S} 1$ in the supporting information).

The largest tsunami wave heights, predicted by our models, are on the order of $300 \mathrm{~m}$ (see Movie S1 in the supporting information). The portion of the tsunami that propagated to the southeast of our proposed impact sites could have traveled up to $150 \mathrm{~km}$ past the $-3940 \mathrm{~m}$ shoreline, creating a wave up to $75 \mathrm{~m}$ high when it reached the shoreline (Figure 11). 

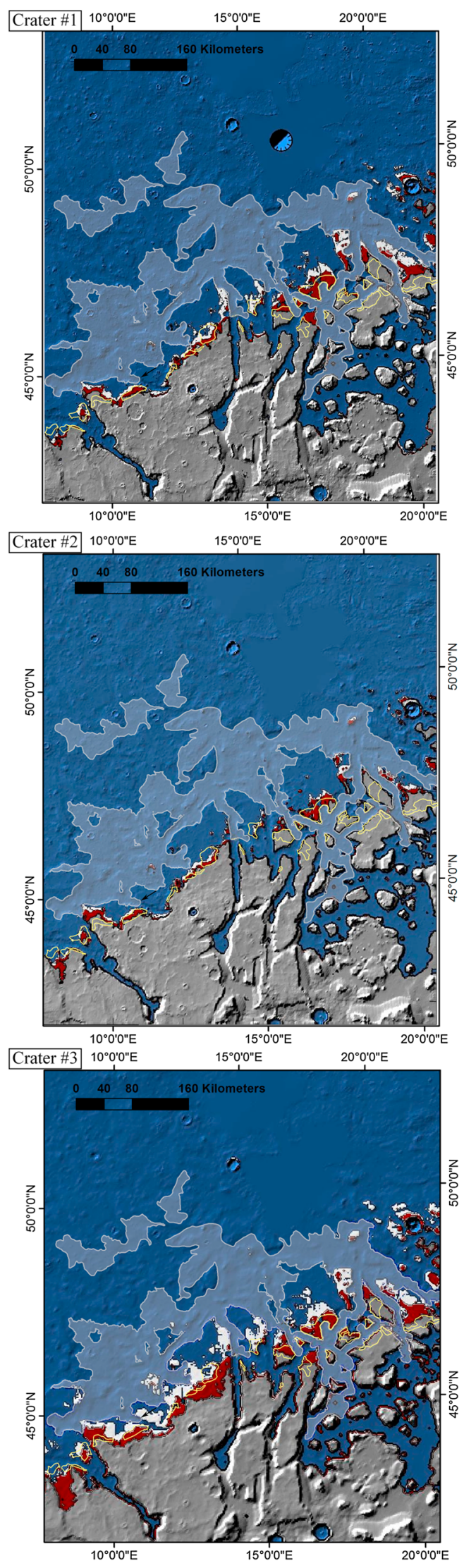

The location and orientation of the $\pi$, and elevated heights reached by the terminal lobate deposits, provide an indication of the size of the impact and where it occurred. Therefore, the direction and propagation distance of the tsunami, predicted by the simulations, were compared to the $\Pi$ unit (Figures 11 and 12). Three impact craters in Acidalia Planitia were investigated as potential tsunami sources, based on their location, size, and apparent age (Figure 8). The tsunami's wave height (at the shore), the direction of propagation, and the runup elevation, were calculated for the location and size of each of the three potential source craters considered. Figure 11 shows the resulting propagation of the tsunamis for the three impact craters assuming a sea level of $-3760 \mathrm{~m}$ (ocean in blue). The $\Pi$ unit (white outline) and the observed backwash areas (yellow outline) are superposed for comparison (white outline in Figure 11). For all craters, the inundation of the coast is more important on the proximal coast than in the narrow valleys where the tsunami waves are attenuated (see red areas in Figure 11). Similarly, the backwash areas are defined in the simulation as the areas where the water associated with the inland propagation of the tsunami flowed back to the local sea level prior to the tsunami event (see white areas in Figure 11). It shows the direction and distance of propagation of the tsunami wave. The red unit shows the resulting inundated area from our numerical

Figure 11. Numerical simulations of the propagation of a tsunami generated by the impact craters \#1, \#2, and \#3, assuming a sea level of $-3760 \mathrm{~m}$ (ocean in blue). The white outline corresponds to the observed lobate deposits with runups. The simulation shows the direction and distance of propagation of the tsunami wave and the resulting inundated area (red). The inundated backwash area is in white color for the simulation and in yellow outlines for the observation. The black arrow shows the location of tsunami lobe on Figure $1 \mathrm{a}$. Colored dots correspond to the measured water thickness and wave amplitude in the supporting information. 


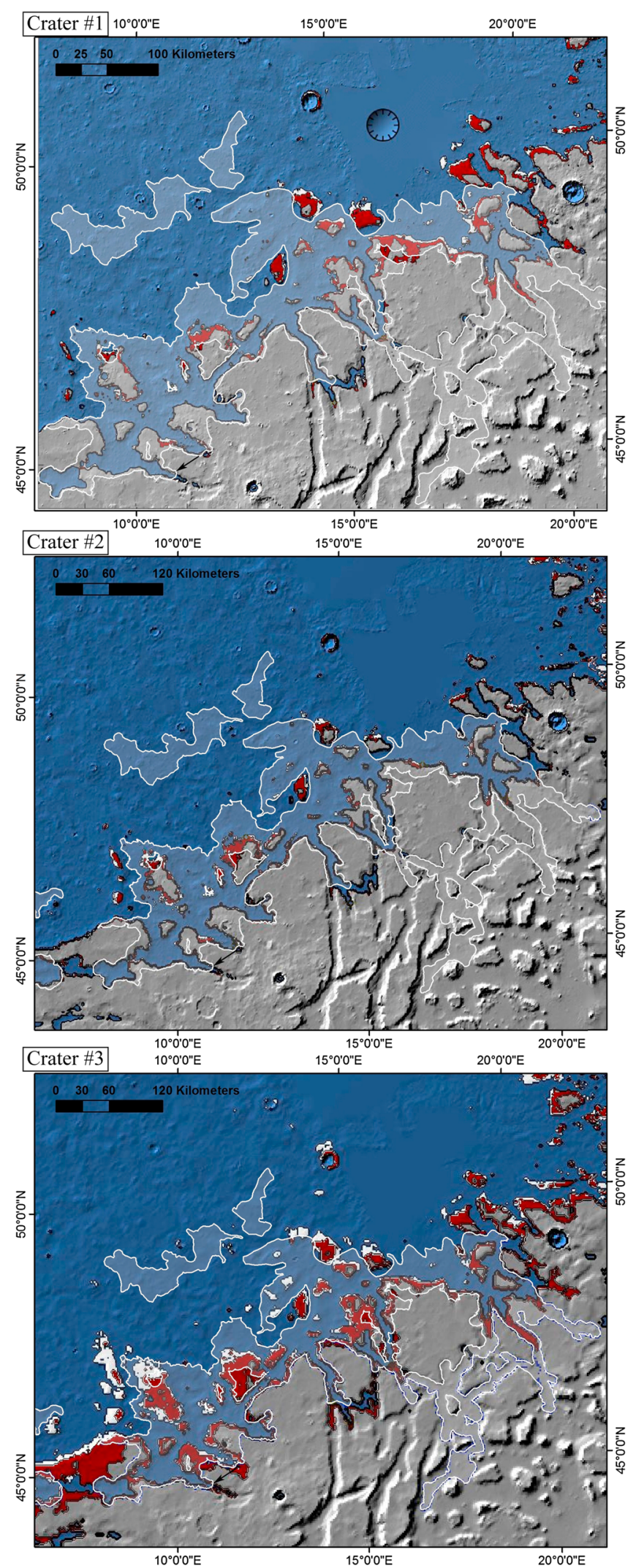

modeling. The white color delineates the inundated backwash area from the modeling. Depending on which impact craters is considered, the location and distribution of inundated areas along the shorelines differ (Figure 11). For craters \#1 and \#3, the inundation areas are maximized because crater \#1 is the closest and crater \#3 is the largest (Figures 11a and 11c). The coastal inundation is greater in the west for crater \#3 in comparison to the other craters because crater \#3 is located to the northwest (Figures 8 and 11c). The predicted inundation areas (red) and backwash areas (white) are consistent with the observed backwash channels (yellow outlines) for crater \#1 and \#3 (Figures 11a and 11c). For a sea level at $-3940 \mathrm{~m}$, the simulated inundation and backwash areas are too far away from the observed backwash areas for craters \#1 and \#2 (Figure 12).

The crater \#3 seems to be the best single candidate because the inundated areas and backwashed areas from the modeling show the best spatial correlation to the $\Pi$ distribution (Figure 11c). Such a spatial correlation strongly supports an origin by impact. The observed distribution of backwash channels is also consistent with those predicted from our simulations only for an ocean shoreline at $-3760 \mathrm{~m}$ (Contact 2) (Figure 11c). From the comparison, the lobate deposits of $\Pi$

Figure 12. Numerical simulations of the propagation of a tsunami generated by the impact craters \#1, \#2, and \#3, assuming a sea level of $-3940 \mathrm{~m}$ (ocean in blue). The light gray area corresponds to the observed lobate deposits with runups. The simulation shows the direction and distance of propagation of the tsunami wave and the resulting inundated area (red). The white color delineates the inundated backwash area. For craters \#2 and \#3, we removed the largest impact craters \#1, which eliminated secondary reflections during the propagation of the tsunami waves. The black arrow shows the location of tsunami lobe on Figure 1a. Colored dots correspond to the measured water thickness and wave amplitude in the supporting information. 
are either localized offshore and inland suggesting that the sediments were deposited by the tsunami waves in both environments (Figure 11).

\section{Discussion}

We identified $T$ unit as a tsunami deposit. The distribution of these lobate deposits and the height of their runups suggest that they originated from within the northern plains and propagated upslope over the dichotomy boundary [Costard et al., 2015]. We used the numerical model VolcFlow [Kelfoun and Druitt, 2005] to compare the propagation of an ocean impact-generated tsunami with the distribution of lobate deposits found along the dichotomy boundary. Here we have combined these two approaches to better constrain the tsunami hypothesis and provide insights into the origin of the arcuate patterned mounds that characterize the $\Pi$ (Figure 1). Our simulations indicate that when the initial tsunami collided with the complex topography along the dichotomy boundary, it gave rise to multiple reflected and refracted waves that propagated back out to sea. We believe that these reflected waves interfered with the late-arriving tsunami waves, which influenced their deposition of entrained sediment, creating the conditions responsible for the characteristic arcuate pattern of the $\Pi$ 's interior mounds. Morphological evidence for the formation of the $\Pi$ by high-energy, debris-laden flows is provided by flow deposits that overtop hills and plateaus that terminate in 10-20 $\mathrm{m}$ thick lobate outer margins (Figures $1 \mathrm{a}$ and 11).

We also have simulated the behavior of a mud ocean by considering it as a Bingham fluid [Johnson, 1970]. The initial wave amplitude being small $(<1 \mathrm{~km})$ compared to the horizontal distance from the impact to the shore ( $>100 \mathrm{~km})$, an initial wave in mud is rapidly attenuated and cannot form a significant tsunami on the shore line. We conclude that the sediment load was low enough that it did not significantly modify the water rheology. As a result, the numerical modelings presented here are for pure water only.

The relatively thick deposits $(\sim 10 \mathrm{~m})$ on terminal lobes near Contact 2 can be addressed by the relatively low gravity on Mars which produces high concentrations of wash load [Komar, 1979] and production of extensive deposits similar to those produced by submarine flows on Earth.

The potential effect of an ice cover on tsunami wave propagation is still an open issue. The propagation of tsunami waves in an ice-covered ocean has not been observed on Earth and there have been no theoretical studies their potential occurrence on Mars. Therefore, our numerical model is based on wave propagation in a fluid, with the potential effect of a thick ice cover still unaddressed.

The possibility of Early Amazonian/Late Hesperian northern ocean (whether entirely liquid, ice covered, or frozen throughout) has also been considered by other investigators [Baker et al., 1991; Clifford and Parker, 2001]. Clifford and Parker [2001] have considered the hydraulic and thermal conditions that gave rise to the elevated source regions of the Late Hesperian outflow channels and explored their implications for the evolution of the early Martian hydrosphere. They concluded that a northern ocean, covering as much as a third of the planet, was likely an initial condition that, depending on the nature of the climate, rate of sublimative/evaporative loss, and potential replenishment from the episodic reflooding of the northern plains by outflow channel activity, may have persisted (or reoccurred) well into the Late Hesperian/Early Amazonian [Baker et al., 1991]. Based on crater counts, outflow channel activity appears to have peaked during the transition between the Late Hesperian and Early Amazonian ( 3 Gyr) but persisted well into the Late Amazonian (as recently as the last 100 Myr [Warner et al., 2009; Neukum et al., 2010]). This history of outflow channel activity is consistent with the presence of a transient northern ocean around $2.9 \mathrm{Gyr}$, in agreement with the detection of tsunami deposits along thumbprint terrains in Arabia Terra. A frozen remnant of a late northern ocean may still be preserved beneath a thick, diffusion-limiting mantle of aeolian dust, fluvial, or volcanic sediments-a possibility supported by the preferential occurrence of cold-climate landforms and fluidized ejecta craters throughout the northern plains, combined with the low regional surface permittivities found by Mars Advanced Radar for Subsurface and lonosphere Sounding (MARSIS) [Mouginot et al., 2012].

\section{Concluding Remarks}

Up until now, the thumbprint terrains have been interpreted as glacial or volcanic landforms; however, their actual origin remains a subject of debate. In Acidalia, the recent discovery of lobate deposits with runups of some $10-20 \mathrm{~m}$ along the dichotomy boundary suggests emplacement by a high-energy tsunami, due to the 
impact of an asteroid into a northern ocean. We used the numerical model VolcFlow to compare the propagation of an ocean impact-generated tsunami with our mapping of the distribution of lobate deposits. Our modeling suggests several impact craters $\sim 30-50 \mathrm{~km}$ in diameter as the potential source of the tsunami events. From our model, the tsunami waves propagated to the southeast part of $\pi$ unit and could have traveled up to $150 \mathrm{~km}$ past the $-3940 \mathrm{~m}$ shoreline, creating a wave up to $75 \mathrm{~m}$ high.

The duration and timing of a northern ocean is a key issue in understanding the recent geological and climatic evolution of Mars. The identification of lobate deposits that emanates from the northern plains and propagates upslope, along the dichotomy boundary provides strong support for an Early Amazonian/Late Hesperian ocean.

The preferential occurrence of cold-climate landforms [Séjourné et al., 2011], of fluidized ejecta craters [Costard, 1989], and the low regional surface permittivities found by MARSIS [Mouginot et al., 2012] throughout the northern plains strongly support the presence of a former northern ocean.

\section{Acknowledgments}

The authors acknowledge the HiRISE Team for the availability of the data on the Web site https://hirise.Ipl.arizona. edu/ and the HRSC Team of the German Aerospace Center (DLR) Berlin, who provided map projected HRSC image data. We acknowledge Chiara Marmo and the Orsay Planetary Picture Library for the data provided and images processing (http://fototek.geol.u-psud.fr). We solved the equations numerically using the code VolcFlow (http://Imv. univ-bpclermont.fr/volcflow/), which has been used to simulate tsunamis (see Texts S2-S4). Two anonymous reviewers are acknowledged for their constructive comment on earlier version of this manuscript that was submitted to Geophysical Research Letters on 8 July 2016. We also thank V. Baker whose comments greatly improved the paper. Authors are funded by the Programme National de Planétologie (PNP) of Centre National de la Recherche Scientifique/Institut National des Sciences de I'Univers, the Centre National d'Etudes Spatiales (CNES), and National Aeronautics and Space Administration (NASA). This is LPI contribution \#\#\#\#\#.

\section{References}

Anderson, J. A., S. C. Sides, D. L. Soltesz, T. L. Sucharski, and K. J. Becker (2004), Modernization of the integrated software for imagers and spectrometers Lunar Planet. Inst. Sci. Conf. 35th, Abstracts 2039.

Baker, V. R., R. G. Strom, V. C. Gulik, J. S. Kargel, G. Komatsu, and V. S. Kale (1991), Ancient oceans, ice sheets and the hydrological cycle on Mars, Nature, 352, 589-594, doi:10.1038/352589a0.

Bryant, E. A. (2001), Tsunami: The Underrated Hazard, pp. 320, Cambridge Univ. Press, Cambridge.

Carr, M. H., and J. W. Head (2003), Oceans on Mars: An assessment of the observational evidence and possible fate, J. Geophys. Res., 108(E5), 5042, doi:10.1029/2002JE001963.

Carr, M. H., and J. W. Head (2010), Geologic history of Mars, Earth Planet. Sci. Lett., 294, 185-203.

Catling, C., C. B. Leovy, S. E. Wood, and M. D. Day (2012), Does the Vastitas Borealis formation contain oceanic or volcanic deposits?, Third Conference on Early Mars: Geologic, Hydrologic, and Climatic Evolution and the Implications for Life, 21-25 May 2012, Lake Tahoe, Nevada, LPI Contribution 1680, Abstract 7031.

Cita, M. C., A. Camerlenghi, and B. Rimoldi (1996), Deep-sea tsunami deposits in the eastern Mediterranean: New evidence and depositional models sedimentary, Geology, 104, 155-173, doi:10.1016/0037-0738(95)00126-3.

Clifford, S. M., and T. J. Parker (2001), The evolution of the Martian hydrosphere: Implications for the fate of a primordial ocean and the current state of the Northern Plains, Icarus, 154, 40-79, doi:10.1006/icar.2001.6671.

Cordonnier, S. (2015), Detecting, modelling and responding to effusive eruptions, Geol. Soc. London, Spec. Publ., 426, 337-343.

Costard, F. M. (1989), The spatial distribution of volatiles in the Martian hydrolithosphere, Earth Moon Planets, 45(3), 265-290, doi:10.1007/ BF00057747.

Costard, F., A. Séjourné, and A. Rygaloff (2015), Evidence of recent flow activity in Acidalia Planitia, Mars EGU, abstract n³842, vol. 17.

Frey, J. V., and M. Jarosewich (1982), Subkilometer Martian volcanoes: Properties and possible terrestrial analogs, J. Geophys. Res., 87(B12), 9867-9879, doi:10.1029/JB087iB12p09867.

Gault, D. E., and C. P. Sonett (1982), Laboratory simulation of pelagic asteroidal impact: Atmospheric injection, benthic topography, and the surface wave radiation field, in Geological Implications of Impacts of Large Asteroids and Comets on the Earth, edited by L. T. Silver and P. H. Schultz, Geol. Soc. Am. Spec. Pap., 190, 69-92.

Giachetti, T., R. Paris, K. Kelfoun, and F. J. Perez-Torrado (2011), Numerical modelling of the tsunami triggered by the Guimar debris avalanche, Tenerife (Canary Islands): Comparison with fieldbased data, Geology, 284, 189-202, doi:10.1016/j.margeo.2011.03.018.

Goto, K., et al. (2011), New insight of tsunami hazard from the 2011Tohoku-oki event, Mar. Geol., 290, 46-50.

Guidat, G., S. Pochat, O. Bourgeois, and O. Souček (2015), Landform assemblage in Isidis Planitia, Mars: Evidence for a 3 Ga old polythermal ice sheet, Earth Planet. Sci. Lett., 411, 253-267.

Hartmann, W. (2005), Martian cratering: Isochron refinement and the chronology of Mars, Icarus, 174, 294-320, doi:10.1016/ j.carus.2004.11.023.

Head, J. W., III, H. Hiesinger, M. Ivanov, M. Kreslavsky, S. Pratt, and B. J. Thomson (1999), Possible ancient oceans on Mars: Evidence from Mars Orbiter Laser Altimeter data, Science, 286, 2134-2137, doi:10.1126/science.286.5447.2134.

Hills, J. G., and M. P. Goda (1998a), Tsunami from asteroid and comet impacts: The vulnerability of Europe Science of Tsunami Hazards, 16, No.1). The Tsunami Society P. O. Box 25218, Honolulu, Hawaii.

Hills, J. G., and M. P. Goda (1998b), Damage fiom the impacts of small asteroids, Planet. Space Sci., 46(2-3), $219-229$.

lijima, Y., K. Goto, K. Minoura, G. Komatsu, and F. Imamura (2014), Hydrodynamics of impact-induced tsunami over the Martian ocean, Planet. Space Sci., 95, 33-44, doi:10.1016/j.pss.2013.09.014.

Johnson, A. M. (1970), Physical Processes in Geology, pp. 577, Freeman, Cooper, San Francisco, Calif.

Jöns, H. P. (1986), Arcuate ground undulations, gelifluxion-like features, in Lunar and Planetary Science Conference, vol. 17, pp. 404-405, Houston, Tex.

Kargel, J. S., V. R. Baker, J. E. Beget, J. F. Lockwood, T. L. Pewe, J. S. Shaw, and R. G. Strom (1995), Evidence of ancient continental-glaciation in the Martian northern plains, J. Geophys. Res., 100(E3), 5351-5368, doi:10.1029/94JE02447.

Kelfoun, K., and T. H. Druitt (2005), Numerical modelling of the emplacement of Socompa rock avalanche, Chile, J. Geophys. Res., 110, B12202, doi:10.1029/2005JB003758.

Kelfoun, K., T. Giachetti, and P. Labazuy (2010), Landslide-generated tsunamis at Réunion Island, J. Geophys. Res., 115, F04012, doi:10.1029/ 2009JF001381.

Komar, P. D. (1979), Comparisons of the hydraulics of water flows in Martian outflow channels with flows of similar scale on Earth, Icarus, 37, $156-181$.

Kreslavsky, M. A., and Head, J. W., (2002), Fate of outflow channel effluents in the northern lowlands of Mars: The Vastitas Borealis formation as a sublimation residue from frozen ponded bodies of water. J. Geophys. Res., 107(E12), 5121, doi:10.1029/2001JE001831. 
Lavigne, F., et al. (2009), Reconstruction of tsunami inland propagation on December 26, 2004 in Banda Aceh, Indonesia, through field investigations, Pure Appl. Geophys., 13(166), 259-281, doi:10.1007/s00024-008-0431-8.

Lockwood, J. F., J. S. Kargel, and R. B. Strom (1992), Thumbprint terrain on the northern plains: A glacial hypothesis Abstracts of the Lunar Planet. Sci. Conf., vol. 23, p. 795.

Lucchitta, B. K. (1981), Mars and Earth: Comparison of cold-climate features, Icarus, 45, 264-303.

Lucchitta, B. K., H. M. Ferguson, and C. Summers (1986), Sedimentary deposits in the northern lowland plains, Mars, J. Geophys. Res., 91 , E166-E174, doi:10.1029/JB091iB13p0E166.

Mahaney, W. C., J. M. Dohm, P. Costa, and D. H. Krinsley (2010), Tsunamis on Mars: Earth analogues of projected Martian sediment, Planet. Space Sci., 58(14), 1823-1831, doi:10.1016/j.pss.2010.08.010.

Malin, M. C., et al. (2007), Context Camera investigation on board the Mars Reconnaissance Orbiter, J. Geophys. Res., 112, E05S04, doi:10.1029/ 2006JE002808.

Matsui, T., I. Takamiya, F. Imamura, and E. Tajika (2001), Tsunami generation and propagation in possible ancient ocean on Mars, in Lunar and Planetary Science Conference, vol. 32, pp. 1716, Houston, Tex.

Melosh, H. J. (1989), Impact Cratering: A Geologic Process, pp. 245, Oxford Univ. Press, New York.

Mouginot, J., A. Pommerol, P. Beck, W. Kofman, and S. M. Clifford (2012), Dielectric map of the Martian northern hemisphere and the nature of plain filling materials, Geophys. Res. Lett., 39, L02202, doi:10.1029/2011GL050286.

Neukum, G., R. Jaumann, and the HRSC Co-Investigator and Experiment Team (2004), HRSC: The High Resolution Stereo Camera of Mars Express ESA SP-1240, ESTEC, Noordwijk.

Neukum, G., A. T. Basilevsky, T. Kneissl, M. G. Chapman, S. Van Gasselt, G. Michael, R. Jaumann, H. Hoffmann, and J. K. Lanz (2010), The geologic evolution of Mars: Episodicity of resurfacing events and ages from cratering analysis of image data and correlation with radiometric ages of Martian meteorites, Earth Planet. Sci. Lett., 294(3), 204-222, doi:10.1016/j.epsl.2009.09.006.

Nomikou, P., et al. (2016), Post-eruptive flooding of Santorini caldera and implications for tsunami generation, Nat. Commun., 13332, doi:10.1038/ncomms13332.

Ormo, J. Shuvalov, V. V., and M. Lindstöm (2002), Numerical modeling for target water depth estimation of marine-target impact craters. J. Geophys. Res., 107(E12), 5120, doi:10.1029/2002JE001865.

Paris, R., et al. (2009), Tsunamis as geomorphic crisis: Lessons from the December 26, 2004 tsunami in Lhok Nga, west Banda Aceh (Sumatra, Indonesia), Geomorphology, 104, 59-72, doi:10.1016/j.geomorph.2008.05.040.

Parker, T. J., D. S. Gorsline, R. S. Saunders, D. C. Pieri, and D. M. Schneeberger (1993), Coastal geomorphology of the Martian northern plains, J. Geophys. Res., 98, 11,061-11,078, doi:10.1029/93JE00618.

Rodríguez, J. A. P., et al. (2016), Tsunami waves extensively resurfaced the shorelines of a receding, early Martian ocean, Nat. Scie. Rep., 6 , 25106, doi:10.1038/srep25106.

Rossbacher, L. A., and S. Judson (1981), Ground ice on Mars: Inventory, distribution, and resulting landforms, Icarus, 45, 39-59.

Salvatore, M. R., and P. R. Christensen (2014), Evidence for widespread aqueous sedimentation in the northern plains of Mars, Geology, 42(5), 423-426, doi:10.1130/G35319.1.

Scott, D. H., and J. R. Underwood Jr. (1991), Mottled terrain: A continuing Martian enigma Lunar Planet. Sci. Conf. XXI, 627-634, Houston, Tex.

Séjourné, A., F. Costard, J. Gargani, R. J. Soare, A. Fedorov, and C. Marmo (2011), Scalloped terrain and small sized polygons in western Utopia, Mars: A new formation hypothesis, Planet. Space Sci., 59(5-6), 412-422, doi:10.1016/j.pss.2011.01.007.

Shuvalov, V. V., and I. A. Trubestkaya (2002), Numerical modeling of marine target impacts, Sol. Syst. Res., 36, 417-430.

Smith, D. E., et al. (2001), Mars Orbiter Laser Altimeter: Experiment summary after the first year of global mapping of Mars, J. Geophys. Res., 106(E10), 23,689-23,722, doi:10.1029/2000JE001364.

Souček, O., O. Bourgeois, S. Pochat, and T. Guidat (2015), A 3 Ga old polythermal ice sheet in Isidis Planitia, Mars: Dynamics and thermal regime inferred from numerical modeling, Earth Planet. Sci. Lett., 426, 176-190, doi:10.1016/j.epsl.2015.06.038.

Tanaka, K. L. (1997), Sedimentary history and mass flow structures of Chryse and Acidalia Planitiae, Mars, J. Geophys. Res., 102(E2), 4131-4149, doi:10.1029/96JE02862.

Tanaka, K. L., J. A. Skinner, and T. M. Hare (2005), Geologic map of the northern plains of Mars, scale 1:15,000,000, U.S. Geol. Surv. Sci. Invest Map, 2888.

Tanaka, K., et al. (2014), Geologic map of Mars U.S. Geol. Surv. Sci. Invest. Map, 3292, scale 1:20,000,000, pamphlet 43 p.

Thomson, B. J., and J. W. Head III (2001), Utopia Basin, Mars: Characterization of topography and morphology and assessment of the origin and evolution of basin internal structure, J. Geophys. Res., 106, 23,209-23,230, doi:10.1029/2000JE001355.

Ward, S. N., and E. Asphaug (2000), Asteroid impact tsunami: A probabilistic hazard assessment, Icarus, 145, 64-78, doi:10.1006/ icar.1999.6336.

Warner, N., S. Gupta, J. P. Muller, J. R. Kim, and S. Y. Lin (2009), A refined chronology of catastrophic outflow events in Ares Vallis, Mars, Earth Planet. Sci. Lett., 288, 58-69, doi:10.1016/j.epsl.2009.09.008.

Wassmer, P., R. Paris, and F. Lavigne (2006), Apports de la photographie aérienne oblique dans l'analyse des impacts environnementaux du tsunami, in Le Tsunami du 26 Décembre 2004 en Indonésie, Rapport Scientifique du Programme TSUNARISQUE. Délégation Interministérielle pour l'aide Post-Tsunami (DIPT), edited by F. Lavigne and R. Paris, pp. 97-113, Ambassade de France en Indonésie. 